\title{
ERAP1 GENE POLYMORPHISMS INFLUENCE THE CLINICAL CHARACTERISTICS OF ANKYLOSING SPONDYLITIS
}

\author{
Marius Cherciü, Luis Ovidiu Popa², Mihai Bojinca ${ }^{3}$, Monica Irina Dutescu ${ }^{4}$, Violeta Bojinca ${ }^{5}$, \\ Teodora Serban ${ }^{3}$, Constantin Bara ${ }^{1}$, Olivia Mihaela Popa ${ }^{1}$ \\ ${ }^{I}$ Department of Immunology and Pathophysiology, Faculty of Medicine, \\ Carol Davila University of Medicine and Pharmacy, Bucharest, Romania \\ ${ }^{2}$ Molecular Biology Department, Grigore Antipa National Museum of Natural History, Bucharest, Romania \\ ${ }^{3}$ Department of Rheumatology, Faculty of Medicine, I.C. Cantacuzino Hospital, \\ Carol Davila University of Medicine and Pharmacy, Bucharest, Romania \\ ${ }^{4}$ Prof. Dr. C.T. Nicolau National Institute of Blood Transfusion, Bucharest, Romania \\ ${ }^{5}$ Department of Rheumatology, Faculty of Medicine, Sf. Maria Hospital, \\ Carol Davila University of Medicine and Pharmacy, Bucharest, Romania
}

\begin{abstract}
Objective. Our aim was to investigate whether two ERAP1 gene variants, rs30187 and rs27044, influence the clinical characteristics of ankylosing spondylitis (AS) (the age of onset and the type of articular manifestations axial or mixed) in Romanian patients.

Methods. We studied 94 AS patients and 139 healthy controls. The method used for genotyping the two nonsynonymous single nucleotide polymorphisms (SNPs) was real-time polymerase chain reaction. Association tests were carried out using PLINK 1.07 software. We analyzed separately the subgroups of AS patients with early onset (age $<30$ years) and late onset (age $>30$ years), as well as the subgroups of patients with axial manifestations and mixed manifestations (axial and peripheral).

Results. Significant association between ERAP1 polymorphisms and AS is only present for patients who experienced an early onset ( $p=0.04$ for $r s 30187$ and $p=0.007$ for rs27044) and not for those with late onset $(p=0.32$ for rs30187 and $p=0.29$ for rs27044). Polymorphism rs30187 is associated only with the axial form of $A S(p=$ $0.02)$, while rs 27044 is associated only with the mixed form of the disease $(p=0.02)$

Conclusions. Our findings demonstrate a consistent association between the studied ERAP1 gene SNPs and certain phenotypic characteristics of AS, suggesting that these gene variants may influence the AS onset and the presence of axial or mixed manifestations of AS.
\end{abstract}

Keywords: ERAP1, ankylosing spondylitis, single nucleotide polymorphisms (SNPs), age of onset, clinical characteristics

\section{INTRODUCTION}

Ankylosing spondylitis (AS) is a chronic arthropathy that primarily affects the spine. The hallmark features of the disease are chronic sacroiliitis and limited spine mobility. Often disabling, the axial involvement can be accompanied by peripheral asymmetrical arthritis, enthesitis or extra articular manifestations.

The prevalence of the disease varies greatly in different populations from just $0.0065 \%$ (1) in Ja- pan, to the highest values encountered in northern Norway (the Sami), 1.8\% (2), being closely related to HLA-B27 prevalence and geographical distribution.

The association between HLA-B27 and AS (between $72 \%$ and $95 \%$ of AS patients are HLA-B27 positive) was identified almost 40 years ago (3-6). It is estimated that HLA-B27 contribution to the total genetic risk of AS is $16-30 \%(7,8)$. While more than $90 \%$ of the risk of disease is genetically determined

Correspondence address:

Olivia Mihaela Popa, PhD, Carol Davila University of Medicine and Pharmacy, 37 Dionisie Lupu street, Bucharest, Romania

E-mail: oliviapopa@yahoo.com 
(9), $50 \%$ of predisposition to AS is caused by the major histocompatibility (MHC) system genes, HLA-B27 alleles being the most important, although other alleles (HLA-B60), may also bear an influence on developing AS (10).

AS presents a genetic model similar to an oligogenic disease (11) and, being obvious that HLA-B27 is not the only genetic modification present, searching for genes outside the major histocompatibility system has become a priority (12).

ERAPl is one of the genes found to be associated with AS. This discovery was possible with the help of three genome wide association studies (GWAS) published in 2007, 2010, 2011 (13-15). Several single nucleotide polymorphisms (SNPs), including rs30187 (Lys528Arg), rs27044 (Gln730Glu), rs2287987 (Met349Val), rs10050860 (Asp575Asn) and rs17482078 (Arg725Gln), were reported associated with $\mathrm{AS}$, and then confirmed in subsequent case-control studies conducted in different populations (16-22).

The most important functions of the ERAP1 molecule, from the perspective of AS pathophysiology, involves cleaving the cell surface receptors of various cytokines, like TNF-R1 (23), IL1-RII (24) and IL-6R $\alpha$ (25), and trimming the antigenic peptides which will to be loaded onto MHC I molecules (including HLA-B27). ERAP1 is involved in the final phase of processing the antigenic epitopes which are brought to an optimum length of 8-9 amino acids. Thus, ERAP1 plays a vital role in generating the antigenic peptides which are presented to CD8 + lymphocytes and natural killer (NK) cells by the antigen presenting cells (APC) (26-29).

This last role seems to be the one conferring the risk of AS, because it was shown that allelic variants of ERAPl gene influence the enzimatic activity of the molecule, inducing a variation in speed and intensity of the epitopes' trimming (30). As a consequence, the ability to expose antigenic peptides (self or non-self) on the APC surface is altered in individuals who present both HLA-B27 and ERAP1 allelic variants associated with high risk for AS (31).

The aim of our study was to investigate whether two ERAP1 gene polymorphisms, rs30187 (Lys528Arg) and rs27044 (Gln730Glu), influence the clinical characteristics of AS (the age of onset and the type of articular manifestations - axial or mixed) in Romanian patients.

\section{PATIENTS AND METHODS}

\section{Case-control groups}

We included in the study 94 AS patients and 139 healthy controls. Detailed characteristics of the enrolled patients and controls are presented in Table 1.

TABLE 1. Characteristics of the AS patients and controls included in the study

\begin{tabular}{|l|c|c|}
\hline Characteristics & $\begin{array}{c}\text { AS Patients } \\
(\mathbf{n = 9 4 )}\end{array}$ & $\begin{array}{c}\text { Controls } \\
(\mathbf{n}=\mathbf{1 3 9})\end{array}$ \\
\hline Mean age (in years) & 37 & 37.8 \\
\hline Median age (in years) & 35 & 35.5 \\
\hline Sex ratio of male:female & $79: 15$ & $71: 68$ \\
\hline HLA-B27 positive & $86.1 \%$ & $10.9 \%$ \\
\hline Axial/Mixed/Peripheral AS & $61.7 \% / 37.3 \% / 1 \%$ & - \\
\hline Anti TNF treatment & $26.6 \%$ & - \\
\hline
\end{tabular}

The patients, diagnosed with AS according to the 1984 modified New York criteria (32), were unrelated individuals consecutively recruited through the Departments of Rheumatology and Internal Medicine of „Dr. I. Cantacuzino“ Hospital and „Sfânta Maria“"Hospital, Bucharest.

The mean age at the AS onset was 27.28 years. In two thirds of the patients the onset of AS was before 30 years of age, and only in $11 \%$ of the patients the disease was firstly diagnosed after the age of 40 , confirming AS as a disease that targets young adults. (Fig. 1).

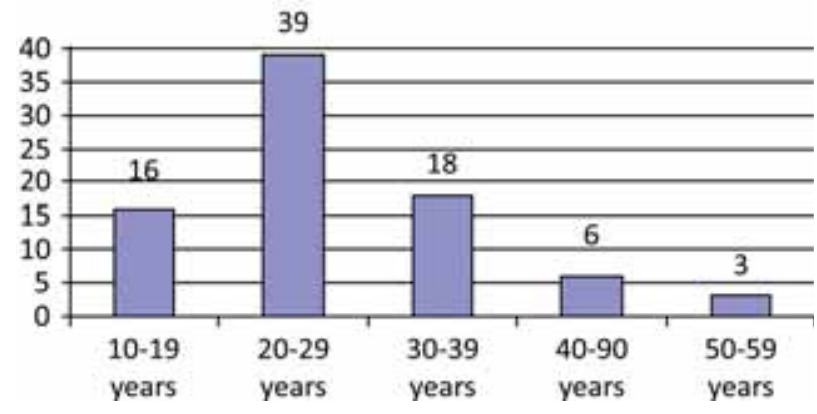

FIGURE 1. The age distribution of the AS onset

Subjects included in the control group were unrelated Caucasian subjects from Romania provided by the National Institute of Blood Transfusion „Prof. Dr. C.T. Nicolau“, Bucharest. They are healthy potential organ donors without symptoms or history of inflammatory rheumatic diseases.

All subjects signed an informed consent form that explained the purpose of the blood sample collection. The study was approved by the local ethics committees. 


\section{Genotyping of the ERAP1 polymorphisms}

The two ERAP1 polymorphisms chosen for this study are rs30187 (Lys528Arg) and rs27044 (Gln$730 \mathrm{Glu}$ ). Both SNPs are located in the coding sequence of the gene. Both are non-synonymous (missense) mutations, which means they change the amino acid coded by the codon which contains them.

The characteristics of the genotyped SNPs are provided in Table 2 .

TABLE 2. ERAP1 single nucleotide polymorphisms genotyped in this study

\begin{tabular}{|l|c|c|c|c|}
\hline SNP & $\begin{array}{c}\text { Messenger } \\
\text { RNA } \\
\text { position }\end{array}$ & $\begin{array}{c}\text { Codon change } \\
\text { (sense and } \\
\text { antisense } \\
\text { strand) }\end{array}$ & $\begin{array}{c}\text { Amino } \\
\text { acid } \\
\text { position }\end{array}$ & $\begin{array}{c}\text { Residue } \\
\text { change }\end{array}$ \\
\hline rs30187 & 1930 & $\begin{array}{c}\text { AAG - AGG } \\
\text { (TTC - TCC) }\end{array}$ & 528 & $\begin{array}{c}\text { K(Lys) - R } \\
\text { (Arg) }\end{array}$ \\
\hline rs27044 & 2535 & $\begin{array}{c}\text { CAA - GAA } \\
\text { (GTT - CTT) }\end{array}$ & 730 & $\begin{array}{c}\text { Q(Gln) - E } \\
\text { (Glu) }\end{array}$ \\
\hline
\end{tabular}

SNP - Single Nucleotide Polymorphism; RNA - Ribonucleic Acid.

The genotyping was performed by Real-Time PCR with TaqMan Allelic Discrimination Assays (C_3056885_10 and C_3056870_10) following the protocol offered by the manufacturer (Applied Biosystems, Foster City, MA, USA) (https://tools.lifetechnologies.com/content/sfs/manuals/TaqManSNPGenotypingAssas man.pdf)

\section{Statistical analysis}

The deviation from Hardy-Weinberg equilibrium (HWE) was tested for both SNPs in the control group (33).

Alleles and genotypes frequencies for each SNP were compared between controls and the subsets of patients depending on the characteristic we wanted to investigate (age of onset, axial or mixed manifestations of the disease).

Association tests were assessed using Fisher's Exact test with PLINK 1.07 software (34) and p values $\leq 0.05$ were considered statistically significant.

\section{RESULTS}

The group of healthy controls showed no deviation from HWE for both investigated SNPs. Allelic frequencies in the control group for both SNPs were within the limits reported for European descendants by HapMap (http://hapmap.ncbi.nlm.nih.gov).

We previously reported the association of these SNPs belonging to ERAPl gene with spondyloarthritis (SpA) in HLA-B27 positive Romanians (35). For AS patients the association was also present when the polymorphisms were analyzed against a random control group (not exclusively HLA-B27 positives).

The focus of this study is the relation between the ERAP1 polymorphisms and two clinical characteristics of AS: age of onset and the axial or mixed (axial and peripheral) manifestations of the disease.

The analysis of the subgroup of patients who experienced an early onset AS (the second and third decade of life) and accounted for $67 \%$ of the patients, and the subgroup of patients with the onset of AS after 30 years of age, showed that significant association between ERAP1 polymorphisms and AS is only present for those who had an early onset.

TABLE 3. Minor allele frequencies and genotypes frequencies for rs30187 and rs27044 in the subgroup of patients with early AS onset (<30 years)

\begin{tabular}{|c|c|c|c|}
\hline SNP & $\begin{array}{l}\text { Controls } \\
(n=139)\end{array}$ & $\begin{array}{c}\text { Early onset AS } \\
\text { (<30 years) } \\
(n=55)\end{array}$ & Statistics \\
\hline \multicolumn{4}{|l|}{ rs30187 } \\
\hline \multirow[b]{2}{*}{ Minor allele T } & Number (frequency) & Number (frequency) & \multirow{2}{*}{$\begin{array}{c}\text { OR } 1.584 \\
95 \% \text { Cl 1.006-2.495 } \\
\mathbf{p}=\mathbf{0 . 0 4}\end{array}$} \\
\hline & $89(32 \%)$ & $47(43 \%)$ & \\
\hline Genotype TT+CT & $15+59(53 \%)$ & $6+35(74.5 \%)$ & \multirow{2}{*}{$\begin{array}{c}\text { OR } 2.572 \\
95 \% \text { Cl } 1.287-5.140 \\
\mathbf{p}=\mathbf{0 . 0 0 6}\end{array}$} \\
\hline Genotype CC & $65(47 \%)$ & $14(25.5 \%)$ & \\
\hline \multicolumn{4}{|l|}{ rs27044 } \\
\hline \multirow[t]{2}{*}{ Minor allele G } & $\begin{array}{c}\text { Number } \\
\text { (frequency) }\end{array}$ & Number (frequency) & \multirow{2}{*}{$\begin{array}{c}\text { OR } 1.911 \\
95 \% \text { Cl 1.184-3.083 } \\
\mathbf{p}=\mathbf{0 . 0 0 7}\end{array}$} \\
\hline & $64(23 \%)$ & $40(36 \%)$ & \\
\hline Genotype GG+CG & $7+50(41 \%)$ & $5+30(63.6 \%)$ & \multirow{2}{*}{$\begin{array}{c}\text { OR } 2.518 \\
95 \% \text { Cl } 1.321-4.799 \\
\mathbf{p}=\mathbf{0 . 0 0 4}\end{array}$} \\
\hline Genotype CC & $82(59 \%)$ & $20(36.6 \%)$ & \\
\hline
\end{tabular}

AS - ankylosing spondylitis; SNP - single-nucleotide polymorphisms; $\mathrm{Cl}$ - 95\% confidence interval; OR - odds ratio, $p$ values $<0.05$ are indicated in bold. 
For the subgroup of patients with AS onset in the second and third decade of life minor allele frequencies, frequencies of genotypes and statistical interpretation are presented in Table 3. A statistically significant association $(p<0.05)$ with SA is observed for each of the two single nucleotide polymorphisms, although more important for $\mathrm{rs} 27044(\mathrm{p}=0.007)$ than for $\mathrm{rs} 30187(\mathrm{p}=0.04)$, both for minor allele frequencies and for the minor allele carriers (TT and CT genotypes).

For the subgroup of AS patients with late onset (age $>30$ years), the frequency of the minor alleles and genotypes of both SNPs were similar to controls $(\mathrm{p}>0.05)$. However, given the small number of patients in this subgroup, further studies are necessary.

Analyzing separately the subgroup of patients with axial AS and the subgroup of patients with axial and peripheral (mixed) manifestations, a particular association of the studied SNP with each form of AS was found.

Thus, in the subgroup of patients with axial AS, the minor allele frequency of rs 30187 is $45 \%$, higher than in the control group (32\%), statistical analysis showing a positive association with the axial form of the disease $(p=0.02)$. At the same time carriers of minor allele (T), CT and TT genotypes, have a higher risk of developing axial AS $(p=0.001)$. Conversely, for the other studied polymorphism (rs27044), the minor allele frequency, although higher in axial AS patients compared with controls, does not associate with this form of disease $(p=0.15)$, nor the carriers of minor allele (genotypes $\mathrm{CG}$ and $\mathrm{GG}$ ) show a higher risk of developing axial AS $(p=0.052)$. (Table 4).
For the subgroup of patients with mixed SA (axial and peripheral manifestations), the results are diametrically opposed. The minor allele frequency of rs 27044 is $36 \%$, higher than in the control group $(23 \%)$, the statistically significant association with this form of disease being confirmed by the $\mathrm{p}$ value $(p=0.02)$. Also, minor allele carriers have a higher risk for developing axial and peripheral manifestations $(\mathrm{p}=0.04)$. (Table 5).

In this subset of patients, rs30187 polymorphism is not associated with the disease $(\mathrm{p}=0.36$ for minor allele frequency and $\mathrm{p}=0.28$ for the frequency of genotypes). (Table 5).

\section{DISCUSSIONS AND CONCLUSIONS}

Our results showed for the first time the association between the studied ERAPI gene variants and early AS onset ( $<30$ years). In addition, the statistical analysis showed that rs30187 is associated only with the axial form of AS, while rs27044 is associated only with the mixed form of the disease.

The two SNPs were initially found to be significantly associated with AS by the Wellcome Trust Case Control Consortium and Australo-AngloAmerican Spondylitis Consortium study published in 2007 (13) and then rs30187 was reconfirmed by another GWAS from 2011 (15). Since then this association was consistently corroborated by many European, North American and Asian studies (1622 ), including the one previously reported by our group (35).

TABLE 4. Minor allele frequencies and genotypes frequencies for rs30187 and rs27044 in the subgroup of patients with axial AS

\begin{tabular}{|c|c|c|c|}
\hline SNP & $\begin{array}{l}\text { Controls } \\
(n=139)\end{array}$ & $\begin{array}{c}\text { AS axial form } \\
(n=55)\end{array}$ & Statistics \\
\hline \multicolumn{4}{|l|}{ rs30187 } \\
\hline \multirow[b]{2}{*}{ Minor allele $\mathrm{T}$} & Number (frequency) & Number (frequency) & \multirow{2}{*}{$\begin{array}{c}\text { OR } 1.706 \\
95 \% \text { Cl } 1.08-2.68 \\
\mathbf{p}=\mathbf{0 . 0 2}\end{array}$} \\
\hline & $89(32 \%)$ & 49 (45\%) & \\
\hline \multirow{2}{*}{$\begin{array}{l}\text { Genotype TT+CT Genotype } \\
\text { CC }\end{array}$} & $15+59(53 \%)$ & $6+37(78 \%)$ & \multirow{2}{*}{$\begin{array}{c}\text { OR } 3.184 \\
95 \% \text { Cl } 1.53-6.47 \\
\mathbf{p}=\mathbf{0 . 0 0 1}\end{array}$} \\
\hline & 65 (47\%) & $12(22 \%)$ & \\
\hline \multicolumn{4}{|l|}{ rs27044 } \\
\hline \multirow{2}{*}{ Minor allele G } & Number (frequency) & Number (frequency) & \multirow{2}{*}{$\begin{array}{c}\text { OR } 1.43 \\
95 \% \text { Cl } 0.87-2.34 \\
p=0.15\end{array}$} \\
\hline & 64 (23\%) & $33(30 \%)$ & \\
\hline \multirow{2}{*}{$\begin{array}{l}\text { Genotype GG+CG } \\
\text { Genotype CC }\end{array}$} & $7+50(41 \%)$ & $2+29(56 \%)$ & \multirow{2}{*}{$\begin{array}{c}\text { OR } 1.85 \\
95 \% \mathrm{Cl} 0.98-3.49 \\
p=0.052\end{array}$} \\
\hline & $82(59 \%)$ & $24(44 \%)$ & \\
\hline
\end{tabular}

AS - ankylosing spondylitis; SNP - single-nucleotide polymorphisms; Cl - 95\% confidence interval; OR - odds ratio, $p$ values $<0.05$ are indicated in bold. 
TABLE 5. Minor allele frequencies and genotypes frequencies for rs 30187 and rs27044 in the subgroup of patients with axial peripheral manifestations

\begin{tabular}{|c|c|c|c|}
\hline SNP & $\begin{array}{l}\text { Controls } \\
(n=139)\end{array}$ & $\begin{array}{l}\text { AS mixed form } \\
(n=33)\end{array}$ & Statistics \\
\hline \multicolumn{4}{|l|}{ rs30187 } \\
\hline \multirow[t]{2}{*}{ Minor allele T } & Number (frequency) & Number (frequency) & \multirow{2}{*}{$\begin{array}{c}\text { OR } 1.295 \\
95 \% \text { Cl } 0.74-2.26 \\
p=0.36\end{array}$} \\
\hline & 89 (32\%) & $25(38 \%)$ & \\
\hline \multirow{2}{*}{$\begin{array}{l}\text { Genotype TT+CT } \\
\text { Genotype CC }\end{array}$} & $15+59(53 \%)$ & $4+17(64 \%)$ & \multirow{2}{*}{$\begin{array}{c}\text { OR } 1.537 \\
95 \% \text { Cl } 0.70-3.36 \\
p=0.28\end{array}$} \\
\hline & $65(47 \%)$ & $12(36 \%)$ & \\
\hline \multicolumn{4}{|l|}{ rs27044 } \\
\hline \multirow[t]{2}{*}{ Minor allele $\mathrm{G}$} & Number (frequency) & Number (frequency) & \multirow{2}{*}{$\begin{array}{c}\text { OR } 1.91 \\
95 \% \text { Cl 1.07-3.39 } \\
\mathbf{p}=\mathbf{0 . 0 2}\end{array}$} \\
\hline & $64(23 \%)$ & $24(36 \%)$ & \\
\hline \multirow{2}{*}{$\begin{array}{l}\text { Genotype GG+CG } \\
\text { Genotype CC }\end{array}$} & $7+50(41 \%)$ & $4+16(61 \%)$ & \multirow{2}{*}{$\begin{array}{c}\text { OR } 2.21 \\
95 \% \text { Cl } 1.01-4.80 \\
\mathbf{p}=\mathbf{0 . 0 4}\end{array}$} \\
\hline & $82(59 \%)$ & $13(39 \%)$ & \\
\hline
\end{tabular}

AS - ankylosing spondylitis; SNP - single-nucleotide polymorphisms; $C l-95 \%$ confidence interval; $O R$ - odds ratio, $p$ values $<0.05$ are indicated in bold.

The current scientific consensus is that the association of ERAP1 gene variants with AS is valid only for HLA-B27 positive individuals, but not for HLA-B27 negative ones $(36,37)$, which proves the consistent role of both genetic associations in AS.

It was found that the enzymatic activity of ERAPI allelic variants is variable, and this translates into a variable processing of the epitopes trimmed by ERAP1 molecule. The minor allele T of rs30187 determines a $40 \%$ lower proteolytic activity compared with the common allele (15). It was also found that the processing speed varies also with the substrate concentration (30). For example, the minor allele $\mathrm{G}$ of rs27044 (Gln730Glu) has a higher processing speed in low substrate concentration compared to the ancestral allele, but when the substrate concentration was high, the processing speed falls (30).

At first glance the intimate mechanism by which the two gene variants affect the enzymatic activity of ERAP1 is not very obvious, because the two studied polymorphisms are not close to the catalytic site of the ERAP1 molecule. However, they may affect the enzymatic activity of ERAP1 as follows:

- rs30187 polymorphism determines an amino acid change, arginine is replacing lysine, in position 528 located on the domain III (hinge type), which may influence the conformational changes that occur during the switch from the open form (enzymatically inactive) to the closed form (enzymatically active) of the ERAP1 molecule $(38,39)$.

- rs27044 polymorphism replaces glutamic acid with glutamine in position 730 which is located on the internal face of the cavity area, part of domain
IV, which accommodates the carboxyl-terminus end of the peptide antigen (39), and thus, possibly affecting the substrate specificity of ERAP1.

By directly influencing the type and quantity of antigenic peptides loaded onto HLA-B27 molecule (40) and exposed on the cell surface to be presented to $\mathrm{CD} 8+\mathrm{T}$ cells and natural killer, these variants gene dictate the type of the cellular immune response in individuals with this genetic profile (presence of high risk ERAP1 gene variants and HLA-B27), which ultimately leads to the initiation of pathophysiological processes that cause ankylosing spondylitis. This pathophysiological hypothesis seems to explain best the association of ERAPl gene polymorphisms studied in HLA-B27 positive AS patients.

The discovery of new genetic associations with genes outside the major histocompatibility complex made possible the important progress in understanding the disease pathophysiology in the last 5-10 years.

Our findings demonstrate a consistent association between the studied ERAP1 gene SNPs and certain phenotypic characteristics of AS, suggesting that these gene variants may influence the AS onset and the presence of axial or mixed manifestations of AS.

In the future, genetic testing for ERAP1 allelic variants associated with high risk of early onset AS could be introduced in the investigative panel necessary for AS diagnosis, similar to HLA-B27. This may help the correct diagnosis of the disease in selected cases of AS, especially at the onset, when the clinical and radiologic picture of the disease is in- 
completely developed and the diagnosis can be difficult.

If subsequent studies will confirm our findings which suggest that rs30187 polymorphism is associated with axial form while rs27044 with mixed form of AS, these two gene variants can attain a predictive value for axial or mixed form of AS the patient may develop.

New lines of research could also investigate whether the presence of these gene variants in an in- dividual can influence the response to the biological treatment; identifying a genetic profile, that ensures a positive response to a type of treatment that is costly and not without side effects, is one of the goals of personalized therapy in modern medicine.

\section{ACKNOWLEDGEMENTS}

OMP was supported by the University of Medicine and Pharmacy „Carol Davila“ Young Research Project TC 28350/04.11.2013

\section{REFERENCES}

1. Hukuda S., Minami M., Saito T., Mitsui H., Matsui N., Komatsubara Y., et al. Spondyloarthropathies in Japan: nationwide questionnaire survey performed by the Japan Ankylosing Spondylitis Society. The Journal of rheumatology. 2001; 28(3):554-9.

2. Johnsen K., Gran J.T., Dale K., Husby G. The prevalence of ankylosing spondylitis among Norwegian Samis (Lapps). The Journal of rheumatology. 1992; 19(10):1591-4.

3. Truog P., Steiger U., Loewi G., Neuhaus K. [HL-A B27 associated rheumatic disease]. Schweiz Med Wochenschr. 1975; 105(50):1733-5

4. Brewerton D.A., Hart F.D., Nicholls A., Caffrey M., James D.C., Sturrock R.D. Ankylosing spondylitis and HL-A 27. Lancet. 1973; 1(7809):904-7.

5. Reveille J.D. The genetic basis of ankylosing spondylitis. Current opinion in rheumatology. 2006; 18(4):332-41.

6. Brionez T.F., Reveille J.D. The contribution of genes outside the major histocompatibility complex to susceptibility to ankylosing spondylitis. Current opinion in rheumatology. 2008; 20(4):384-91.

7. Sims A.M., Wordsworth B.P., Brown M.A. Genetic susceptibility to ankylosing spondylitis. Current molecular medicine. 2004; 4(1):13-20.

8. Maksymowych W.P., Rahman P., Reeve J.P., Gladman D.D., Peddle L., Inman R.D. Association of the IL1 gene cluster with susceptibility to ankylosing spondylitis: an analysis of three Canadian populations. Arthritis and rheumatism. 2006; 54(3):974-85.

9. Brown M.A. Breakthroughs in genetic studies of ankylosing spondylitis. Rheumatology. 2008; 47(2):132-7.

10. Reveille J.D. The genetic basis of spondyloarthritis. Annals of the rheumatic diseases. 2011; 70 Suppl 1:i44-50.

11. Brown M.A., Laval S.H., Brophy S., Calin A. Recurrence risk modelling of the genetic susceptibility to ankylosing spondylitis. Annals of the rheumatic diseases. 2000; 59(11):883-6.

12. Laval S.H., Timms A., Edwards S., Bradbury L., Brophy S., Milicic A., et al. Whole-genome screening in ankylosing spondylitis: evidence of non-MHC genetic-susceptibility loci. American journal of human genetics. 2001; 68(4):918-26.

13. Burton P.R. C.D., Cardon L.R., Craddock N., Deloukas P., Duncanson A., et al, for The Australo-Anglo-American Spondylitis Consortium (TASC). Association scan of 14,500 nonsynonymous SNPs in four diseases identifies autoimmunity variants. Nat Genet. 2007; 39(11):1329-37.

14. The Australo-Anglo-American Spondyloarthritis Consortium (TASC) RJ, et al. Genome-wide association study of ankylosing spondylitis identifies non-MHC susceptibility loci. Nat Genet. 2010; 42(2):123-7.

15. Evans D.M., Spencer C.C., Pointon J.J., Su Z., Harvey D., Kochan G, et al. Interaction between ERAP1 and HLA-B27 in ankylosing spondylitis implicates peptide handling in the

mechanism for HLA-B27 in disease susceptibility. Nat Genet. 2011; 43(8):761-7.

16. Pimentel-Santos F.M., Ligeiro D., Matos M., Mourao A.F., Sousa E., Pinto P., et al. Association of IL23R and ERAP1 genes with ankylosing spondylitis in a Portuguese population. Clinical and experimental rheumatology. 2009; 27(5):800-6.

17. Maksymowych W.P., Inman R.D., Gladman D.D., Reeve J.P., Pope A., Rahman P. Association of a specific ERAP1/ARTS1 haplotype with disease susceptibility in ankylosing spondylitis. Arthritis and rheumatism. 2009; 60(5):1317-23.

18. Harvey D., Pointon J.J., Evans D.M., Karaderi T., Farrar C., Appleton L.H., et al. Investigating the genetic association between ERAP1 and ankylosing spondylitis. Hum Mol Genet. 2009; 18(21):4204-12.

19. Choi C.B., Kim T.H., Jun J.B., Lee H.S., Shim S.C., Lee B., et al. ARTS1 polymorphisms are associated with ankylosing spondylitis in Koreans. Annals of the rheumatic diseases. 2010; 69(3):582-4.

20. Szczypiorska M., Sanchez A., Bartolome N., Arteta D., Sanz J., Brito E., et al. ERAP1 polymorphisms and haplotypes are associated with ankylosing spondylitis susceptibility and functional severity in a Spanish population. Rheumatology. 2011; 50(11):1969-75.

21. Li C., Lin Z., Xie Y., Guo Z., Huang J., Wei Q., et al. ERAP1 is associated with ankylosing spondylitis in Han Chinese. The Journal of rheumatology. 2011; 38(2):317-21.

22. Mahmoudi M., Jamshidi A.R., Amirzargar A.A., Farhadi E., Nourijelyani K., Fallahi S., et al. Association between endoplasmic reticulum aminopeptidase-1 (ERAP-1) and susceptibility to ankylosing spondylitis in Iran. Iranian journal of allergy, asthma, and immunology. 2012; 11(4):294-300.

23. Cui X., Hawari F., Alsaaty S., Lawrence M., Combs C.A., Geng W., et al. Identification of ARTS-1 as a novel TNFR1-binding protein that promotes TNFR1 ectodomain shedding. J Clin Invest. 2002; 110(4):515-26.

24. Cui X., Rouhani F.N., Hawari F., Levine S.J. Shedding of the type II IL-1 decoy receptor requires a multifunctional aminopeptidase, aminopeptidase regulator of TNF receptor type 1 shedding. J Immunol. 2003; 171(12):6814-9.

25. Cui X., Rouhani F.N., Hawari F., Levine S.J. An aminopeptidase, ARTS-1, is required for interleukin-6 receptor shedding. The Journal of biological chemistry. 2003; 278(31):28677-85

26. York I.A., Chang S.C., Saric T., Keys J.A., Favreau J.M., Goldberg A.L., et al. The ER aminopeptidase ERAP1 enhances or limits antigen presentation by trimming epitopes to 8-9 residues. Nature immunology. 2002; 3(12):1177-84.

27. Serwold T., Gonzalez F., Kim J., Jacob R., Shastri N. ERAAP customizes peptides for MHC class I molecules in the endoplasmic reticulum. Nature. 2002; 419(6906):480-3.

28. Saveanu L. Concerted peptide trimming by human ERAP1 and ERAP2 aminopeptidase complexes in the endoplasmic reticulum. Nat Immunol. 2005; 6:689-97. 
29. Hattori A., Tsujimoto M. Processing of antigenic peptides by aminopeptidases. Biological \& pharmaceutical bulletin. 2004; 27(6):777-80.

30. Evnouchidou I., Birtley J., Seregin S., Papakyriakou A., Zervoudi E., Samiotaki M., et al. A common single nucleotide polymorphism in endoplasmic reticulum aminopeptidase 2 induces a specificity switch that leads to altered antigen processing. J Immunol. 2012; 189(5):2383-92.

31. Seregin S.S., Rastall D.P., Evnouchidou I., Aylsworth C.F., Quiroga D., Kamal R.P., et al. Endoplasmic reticulum aminopeptidase-1 alleles associated with increased risk of ankylosing spondylitis reduce HLA-B27 mediated presentation of multiple antigens. Autoimmunity. 2013; 46(8):497-508.

32. van der Linden S., Valkenburg H.A., Cats A. Evaluation of diagnostic criteria for ankylosing spondylitis. A proposal for modification of the New York criteria. Arthritis and rheumatism. $1984 ; 27(4): 361-8$.

33. Wigginton J.E., Cutler D.J., Abecasis G.R. A note on exact tests of Hardy-Weinberg equilibrium. Am J Hum Genet. 2005; 76:887-93.

34. Purcell S., Neale B., Todd-Brown K., Thomas L., Ferreira M.A. Bender D., et al. PLINK: a tool set for whole-genome association and population-based linkage analyses. American journal of human genetics. 2007; 81(3):559-75.

35. Cherciu M., Popa L.O., Bojinca M., Dutescu M.I., Bojinca V., Bara C., et al. Functional variants of ERAP1 gene are associated with HLA-B27 positive spondyloarthritis. Tissue antigens. 2013; 82(3):192-6.

36. Reveille J.D., Sims A.M., Danoy P., Evans D.M., Leo P., Pointon J.J., et al. Genome-wide association study of ankylosing spondylitis identifies non-MHC susceptibility loci. Nat Genet. 2010; 42(2):123-7.

37. Brown M.A. Progress in the genetics of ankylosing spondylitis. Briefings in functional genomics. 2011; 10(5):249-57.

38. Nguyen T.T., Chang S.C., Evnouchidou I., York I.A., Zikos C., Rock K.L., et al. Structural basis for antigenic peptide precursor processing by the endoplasmic reticulum aminopeptidase ERAP1. Nature structural \& molecular biology. 2011; 18(5):604-13.

39. Kochan G., Krojer T., Harvey D., Fischer R., Chen L., Vollmar M., et al. Crystal structures of the endoplasmic reticulum aminopeptidase-1 (ERAP1) reveal the molecular basis for $\mathrm{N}$-terminal peptide trimming. Proceedings of the National Academy of Sciences of the United States of America. 2011; 108(19):7745-50.

40. García-Medel N., Sanz-Bravo A., Van Nguyen D., Galocha B., Gómez-Molina P., Martín-Esteban A., et al. Functional Interaction of the Ankylosing Spondylitis-associated Endoplasmic Reticulum Aminopeptidase 1 Polymorphism and HLA-B27 in Vivo. Molecular \& Cellular Proteomics : MCP. 2012; 11(11):1416-29. 